\title{
Antifibrotic Effects of Pioglitazone at Low Doses on the Diabetic Rat Kidney Are Associated with the Improvement of Markers of Cell Turnover, Tubular and Endothelial Integrity, and Angiogenesis
}

\author{
Jorge E. Tobllia ${ }^{a}$ Gabriel Cao ${ }^{a}$ Jorge F. Giani ${ }^{b}$ Margarita Angerosa ${ }^{a}$ \\ Fernando P. Dominici ${ }^{\mathrm{b}}$ Nestor F. Gonzalez-Cadavid ${ }^{\mathrm{c}-\mathrm{e}}$ \\ a Laboratory of Experimental Medicine, Hospital Alemán, and ' Instituto de Química y Fisicoquímica Biológicas, \\ UBA-CONICET, Buenos Aires, Argentina; ' Urology Research Laboratory, Los Angeles Biomedical Research \\ Institute at Harbor-UCLA Medical Center, Torrance, Calif., d Department of Urology, David Geffen School of \\ Medicine at UCLA, and ' Department of Internal Medicine, Charles Drew University, Los Angeles, Calif., USA
}

\section{Key Words}

Diabetic nephropathy $\cdot$ Thiazolidinediones $\cdot$ Peroxisome proliferator-activated receptor- $\gamma \cdot$ Metabolic syndrome $\cdot$ Fibrosis - Inflammation $\cdot$ ZDF fa/fa rat $\cdot$ Nitric oxide synthase $\cdot$ VEGF $\cdot$ Megalin

\begin{abstract}
Background/Aims: Pioglitazone and other thiazolidinediones are renoprotective in diabetic nephropathy at doses that normalize glycemia, presumably as a consequence of glycemic control. However, low doses of pioglitazone that did not normalize glycemia in rat models of type 2 diabetes prevented tubulointerstitial fibrosis and glomerulosclerosis through counteracting inflammation, oxidative stress, cell cycle arrest, and fibrosis. The current work tested whether this low-dose treatment also reduces other fibrosis and inflammation factors in the diabetic kidney and prevents tubular cell loss, endothelial damage, and abnormal angiogenesis. Methods: ZDF fa/fa rats (ZDF) were fed for 4 months chow with $0.001 \%$ pioglitazone, and the untreated ZDF and the non-diabetic lean Zucker rats (LZR) received regular
\end{abstract}

\section{KARGER}

Fax +41613061234 E-Mail karger@karger.ch www.karger.com
(C) 2010 S. Karger AG, Basel

Accessible online at: www.karger.com/kbr chow. Proteinuria, creatinine clearance, blood pressure, and renal quantitative histopathology markers were determined. Results: Correction of renal function in ZDF by pioglitazone, occurring with a glycemia $>250 \mathrm{mg} / \mathrm{dl}$, was accompanied by normalization of the renal levels of connective tissue growth factor and fibronectin (fibrosis), TNF- $\alpha$, interleukin- 6 and MCP-1 (inflammation), megalin (tubular cells), the PCNA/caspase-3 ratio (positive cell turnover), VEGF (abnormal angiogenesis), and the ratio between eNOS and iNOS (endothelial dysfunction). Conclusion: This supports mechanisms for the renoprotective effects of pioglitazone in diabetes additional to glycemic control.

Copyright $\odot 2010$ S. Karger AG, Basel

\section{Introduction}

The thazolidinediones, a group of drugs that bind to the peroxisome proliferator-activated receptor- $\gamma$ (PPAR$\gamma$ ), are widely used for the treatment of type 2 diabetes and they lower blood glucose primarily by improving insulin sensitivity in peripheral tissues [1]. Since diabetic 
nephropathy (DN) is the most common cause of endstage kidney disease and the leading cause of death in diabetic patients [2], and hyperglycemia and metabolic syndrome are strongly associated with chronic kidney disease [3], the prevailing view is that the protective effects of these drugs on the diabetic kidney [4-6] are due to their ability to exert glycemic control and to reduce blood pressure. However, this interpretation does not consider the pleiotropism of PPAR- $\gamma$ agonists, that exceeds their systemic effects and extends to direct local binding to tissue PPAR- $\gamma$ that may directly counteract chronic inflammation, oxidative stress, cytokine release, and eventually fibrosis, particularly in the cardiovascular and renal systems $[7,8]$. These mechanisms are of special relevance to $\mathrm{DN}$, characterized by tubulointerstitial fibrosis and glomerulosclerosis [9-11], and would contribute to the lowering of blood pressure that would in turn hemodynamically stimulate the correction of the renal histopathology due to a combination of systemic and local effects.

The protective effects of thiazolidinediones on the diabetic kidney at doses that control glycemia have been shown in humans [12-15], and in rodent models of type 1 diabetes, such as the streptozotocin-injected rat $[12,16$, 17], but in fact these models do not represent the complexity of the impact of obesity and other factors of the metabolic syndrome and the influence of glycemic control. The more widely used rat models of type 2 diabetes are the obese Zucker fa/fa rat (OZR) and the Zucker diabetic fatty fa/fa rat (ZDF) that differ in the facts that the OZR is considerably more obese and hyperinsulinemic, and is less hyperglycemic than the ZDF [18]. Several aspects of the pathophysiology of glomerulosclerosis and of tubulointerstitial fibrosis in relation to hyperglycemia have been clarified in these strains [e.g. 19, 20]. A clinically used thazolidinedione, pioglitazone, has been reported to be protective for the diabetic kidney, at doses that normalize glycemia either per se or through enhancing the renoprotective effects of an ATIIR-1 inhibitor in the OZR, and other agonists such as rosiglitazone and troglitazone exerted similar effects in the ZDF [4-6, 21].

Despite this evidence, it was not clear on whether the renoprotection exerted by pioglitazone and other thoazolidinediones in type $2 \mathrm{DN}$ is due exclusively to normalizing glycemia via their insulin sensitizer effects, or an intrinsic independent and local mechanism would also contribute. Obviously, the reported beneficial effects of PPAR- $\gamma$ agonists in models of type 1 diabetes $[3,16,17]$, where these drugs do not control glycemia, would support the latter view. Our recent study in the OZR, with a low dose of pioglitazone given for 5 months that does not change the hyperglycemia of $250 \mathrm{mg} / \mathrm{dl}$ seen in this strain [22], demonstrated the prevention of renal tissue damage and fibrosis, as evidenced by the glomerulosclerosis, tubulointerstitial fibrosis, tubular atrophy and podocyte injury indexes, as well as by the reduction in the markers of oxidative stress and inflammation. Essentially similar results were found in the ZDF, where glycemia is higher, but was not reduced below the $250 \mathrm{mg} / \mathrm{dl}$ level, showing that blood pressure, proteinuria and creatinine clearance were however virtually normalized [22]. These results are in agreement with a study with pioglitazone at double the dose of our work given to Otsuka Long-Evans Tokushima fatty (OLETF) rats, which ameliorated DN without changing $\mathrm{HbA}_{1 \mathrm{c}}$ levels as a marker of cumulative hyperglycemia impact [23]. This is also in agreement with our previous demonstration of the antifibrotic effects of pioglitazone independently of glycemic control in the corporal smooth muscle tissue of the penis in the OZR [24].

Taken together, these results suggest that pioglitazone, and by inference other thiazolidinediones, protect the diabetic kidney, in addition to their conventional effects on glycemic control and the lowering of blood pressure, by local antioxidative and anti-inflammatory mechanisms in combination with a resulting or parallel antifibrotic effect. Pioglitazone counteracts in vitro, where insulin sensitization does not operate, the podocycle cell cycle arrest and apoptosis, with the consequent podocyte loss and hypertrophy, induced by hyperglycemia [25]. The effects of pioglitazone and PPAR- $\gamma$ agonists through glycemic control and local mechanisms on other landmarks of diabetes nephropathy, such as abnormal angiogenesis, endothelial dysfunction, or even key markers of renal fibrosis, are less clear.

In the current work we aimed to expand our previous findings by confirming with additional markers the protective effects of low doses of pioglitazone on renal fibrosis and inflammation in the ZDF, and associating them with new mechanistic insights based on the modulation by the drug of tubular pathology, cell replication, apoptosis, angiogenesis, and the eNOS/iNOS balance.

\section{Methods}

Animals and Treatments

All the experiments were approved by the Institutional Animal Care and Use Committee (IACUC) of Hospital Alemán, Buenos Aires, Argentina, and of LABioMed at Harbor-UCLA, Torrance, Calif., USA, and according to the NIH Guide for the Care and Use of Laboratory Animals. Twelve-week-old male Zucker 
diabetic fatty rats (ZDF) and control lean (LZR) (Charles River Laboratories, Wilmington, Mass., USA) were housed in individual cages at $21 \pm 2{ }^{\circ} \mathrm{C}$ and a 12 -hour light/darkness cycle (7 a.m.7 p.m.), and divided into three groups ( $\mathrm{n}=8$ /group), similar to some experimental groups used previously [22]: G1: ZDF, fed regular Purina 5008 chow; G2: ZDF, fed with chow containing $0.001 \%$ ('low-dose') pioglitazone, calculated from the daily food eaten as an approximate dose of $0.6 \mathrm{mg} / \mathrm{kg} /$ day, and G3: LZR, fed regular chow. Blood for biochemical determinations was withdrawn at baseline and then monthly throughout the experiment. After 4 months of treatment all rats were euthanized by subtotal exsanguination under anesthesia (sodium thiopental, i.p.). The kidneys were rapidly excised, weighed and harvested, fixing the left kidneys in $10 \%$ neutral buffered formalin, followed by embedding in paraffin for histochemical and quantitative immunohistochemical studies. The right kidneys were preserved by immersing in liquid nitrogen and storing at $-80^{\circ} \mathrm{C}$.

\section{Blood Pressure and Biochemical Determinations}

At baseline and then monthly, systolic blood pressure and diastolic blood pressure were measured by a non-invasive pressure device using volume pressure recording, CODA 2 (Kent Scientific Co., Torrington, Conn., USA). Measurements were obtained in non-anesthetized rats restrained in a thermic plastic chamber [22].

After 14-hour fasting, rat blood samples were collected and $\alpha$ smooth muscle actin and sera were obtained from duplicate specimens and frozen at $-20^{\circ} \mathrm{C}$. $\alpha$-Smooth muscle actin glucose levels were measured by the glucose oxidase method with an Automatic Analyzer (Hitachi 911, Tokyo, Japan). Serum cholesterol and triglycerides were assessed according to standard methods. Serum insulin was determined by sensitive rat insulin RIA kit (SRI13; Linco Research, St. Charles, Mo., USA). Serum electrolytes were determined by standard methods.

Immunohistochemical and Immunofluorescence Procedures

For immunohistochemical determinations, paraffin-embedded 3- $\mu \mathrm{m}$ tissue sections were deparaffinized and dehydrated. Endogenous peroxide activity was blocked by treating with $0.5 \%$ $\mathrm{H}_{2} \mathrm{O}_{2}$ in methanol for $30 \mathrm{~min}$. Immunohistochemical assays were conducted essentially as previously reported [22]. The following antibodies were used: (1) goat anti-rat TNF- $\alpha$ AF-510NA, 1:50 (R\&D Systems, Inc., Minneapolis, Minn., USA); (2) mouse anti-human VEGF (sc7269), 1:150; (3) goat anti-mouse IL-6 (sc1265), 1:100; (4) goat anti-human fibronectin (sc6952), 1:100; (5) goat anti-human CTGF (sc14939), 1:50; (6) rabbit polyclonal IgG anti-MCP-1 (ab-7202; Abcam, Cambridge, UK), 1:100; (7) rabbit anti-human eNOS or NOS3 (sc654), 1:150; (8) rabbit anti-human iNOS or NOS2 (sc651), 1:150; (9) mouse antirat PCNA (sc56), 1:100 (2-8 from Santa Cruz Biotechnology, Inc., Santa Cruz, Calif., USA); (10) rabbit anti-human caspase-3 AB-3623, 1:50 (Chemicon International, Inc., Temecula, Calif., USA), and (11) mouse anti-rat ED1 MAB1435, 1:100 (Chemicon International, Inc.).

Immunostaining was carried out with a commercial modified avidin-biotin-peroxidase complex technique, Vectastain ABC kit (Universal Elite, Vector Laboratories, Calif., USA), and counterstaining with hematoxylin. For immunofluorescence observations, frozen sections $(5 \mu \mathrm{m})$ were treated with a goat polyclonal IgG anti-megalin (P-20) (1:50, sc16478; Santa Cruz Biotechnolo- gy, Inc.) followed by donkey anti-goat IgG-FITC (1/100) (sc2024; Santa Cruz Biotechnology, Inc.).

In all cases, negative controls consisted of histological sections incubated with PBS rather than the primary antibody. Immunostaining was visualized on a Nikon E400 fluorescence microscope equipped with a high-pressure mercury lamp. Images were acquired with a digital camera and processed (Nikon Instrument Group, Melville, N.Y., USA).

\section{Quantitative Image and Morphological Analysis}

Five stained histological sections were studied for each kidney. All tissue samples were evaluated independently by two investigators without prior knowledge of the group to which the rat belonged. All measurements were carried out on 20 fields per tissue section, using an image analyzer Image-Pro Plus version 4.5 for Windows (Media Cybernetics, LP, Silver Spring, Md., USA). Data were averaged and the results were expressed as a percentage of positive staining $/ \mathrm{mm}^{2}$ and number of cells with positive staining $/ \mathrm{mm}^{2}$ when appropriated.

\section{Immunoprecipitation and Immunoblotting}

Kidney samples were homogenized in 10 volumes of a solubilization buffer containing 1\% Triton X-100 Sigma Ultra (Sigma, St. Louis, Missouri, Mo., USA), together with protease inhibitors. Equal amounts of solubilized proteins $(80 \mathrm{mg})$ were boiled in reducing sample buffer and resolved by SDS-PAGE. Western transfer of proteins to polyvinylidene difluoride membranes was performed. The membranes were then incubated overnight with the following antibodies (1:1,000): anti-CTGF (sc14939), anti-PCNA (sc56), anti-caspase-3 (AB-3623), anti-VEGF (sc7269), anti-iNOS (sc651), anti-eNOS (sc654). After blocking membranes were incubated for $1 \mathrm{~h}$ with goat anti-rabbit IgG horseradish peroxidase (HRP) secondary antibody (for caspase-3, iNOS and eNOS) or goat anti-goat IgG-HRP (for CTGF) or goat anti-mouse IgG-HRP (for PCNA and VEGF). Specific bands were detected by enhanced chemiluminescence (Amersham, Piscataway, N.J., USA), and their intensities were quantitated by digital densitometry. Each marker luminometry determination was performed simultaneously for all specimens. Densitometric values for marker bands are expressed as arbitrary units for each gel. The intensity of the housekeeping $\beta$-actin band was used to normalize the marker values in each gel.

\section{Statistical Method}

Values were expressed as mean \pm SD. All statistical analyses were performed using absolute values and processed through GraphPad Prism, version 5.0 (GraphPad Software, Inc., San Diego, Calif., USA). The assumption test to determine the gaussian distribution was performed by the Kolmogorov-Smirnov method. For parameters with gaussian distribution, comparisons among groups were carried out using one-way analysis of variance (ANOVA) followed by the Bonferroni's test, and two-way ANOVA for repeated measures was used as appropriate. For those parameters like histological data with non-gaussian distribution, comparisons were performed by Kruskal-Wallis test (non-parametric ANOVA) and Dunn's multiple comparison test. A value of $\mathrm{p}<0.05$ was considered significant. 
Table 1. Body weight, blood pressure and laboratory parameters

a Baseline

\begin{tabular}{lccc}
\hline & ZDF $(\mathrm{n}=8)$ & ZDF + PGT $(\mathrm{n}=8)$ & LZR $(\mathrm{n}=8)$ \\
\hline Body weight, g & $397.1 \pm 20.0$ & $400.7 \pm 18.2$ & $265.9 \pm 15.9^{*}$ \\
Systolic blood pressure, mm Hg & $122.5 \pm 2.8$ & $122.8 \pm 3.5$ & $120.2 \pm 3.3$ \\
Diastolic blood pressure, mm Hg & $75.4 \pm 2.1$ & $74.9 \pm 2.2$ & $73.5 \pm 1.9$ \\
Glycemia, mg/dl & $395.6 \pm 40.6$ & $404.5 \pm 35.1$ & $96.0 \pm 14.4^{*}$ \\
Serum insulin, ng/ml & $38.6 \pm 5.9$ & $37.3 \pm 5.2$ & $5.1 \pm 0.9^{*}$ \\
Triglycerides, mg/l & $598.8 \pm 45.9$ & $601.3 \pm 55.7$ & $35.9 \pm 9.7^{*}$ \\
Cholesterol, mg/l & $145.7 \pm 20.1$ & $153.3 \pm 18.7$ & $55.6 \pm 4.8^{*}$ \\
Creatinine clearance, $\mathrm{ml} / \mathrm{min}$ & $3.2 \pm 0.4$ & $3.1 \pm 0.5$ & $3.0 \pm 0.3$ \\
Proteinuria, mg/day & $18.3 \pm 5.0$ & $20.3 \pm 4.2$ & $2.3 \pm 0.1^{*}$ \\
\hline
\end{tabular}

b At the end of the experiment (4 months)

\begin{tabular}{lccc}
\hline Body weight, g & $502.6 \pm 14.3$ & $484.2 \pm 16.4$ & $396.9 \pm 20.2^{*}$ \\
Systolic blood pressure, mm Hg & $160.5 \pm 5.1$ & $134.1 \pm 4.2^{* *}$ & $123.8 \pm 3.7^{*}$ \\
Diastolic blood pressure, mm Hg & $96.0 \pm 2.8$ & $81.8 \pm 2.3^{* *}$ & $74.1 \pm 2.2^{*}$ \\
Glycemia, mg/dl & $475.6 \pm 50.2$ & $243.3 \pm 30.7^{* *}$ & $115.8 \pm 10.5^{*}$ \\
Serum insulin, ng/ml & $8.8 \pm 3.1$ & $10.1 \pm 2.8$ & $3.4 \pm 1.2^{*}$ \\
Triglycerides, mg/l & $587.3 \pm 59.4$ & $223.6 \pm 21.6^{* *}$ & $39.5 \pm 8.4^{*}$ \\
Cholesterol, mg/l & $176.5 \pm 23.1$ & $95.2 \pm 10.6^{* *}$ & $57.2 \pm 4.6^{*}$ \\
Creatinine clearance, ml/min & $2.2 \pm 0.2^{*}$ & $2.9 \pm 0.3$ & $3.0 \pm 0.2$ \\
Proteinuria, mg/day & $234.1 \pm 30.2$ & $56.3 \pm 9.1^{* *}$ & $7.3 \pm 2.5^{*}$
\end{tabular}

Values are mean \pm SD. ${ }^{*} \mathrm{p}<0.01$ vs. all groups. ${ }^{* *} \mathrm{p}<0.01$ vs. ZDF. PGT $=$ Pioglitazone.

\section{Results}

Pioglitazone given at the selected low dose to the ZDF for 4 months did not virtually reduce blood glucose below the $243 \mathrm{mg} / \mathrm{dl}$ previously established as threshold in both the ZDF and the OZR [22], as evidenced by the time course (not shown) represented by the basal and final values (table 1 ). The latter were still nearly 2.5 -fold higher than in the LZR and similar to the hyperglycemia that in the OZR remained unchanged in the low-dose pioglitazone treatment [22]. As expected, body weight was not affected in the moderately obese ZDF. Although triglycerides and cholesterol were reduced as compared to basal values and those in the untreated ZDF, they were still considerably elevated in comparison to the LZR. Serum insulin remained unchanged and at the low levels that characterize the progressive hypoinsulinemia found in this strain. Taken together, this confirms the premise that pioglitazone at this low dose, despite reducing glycemia, does not exert an effective metabolic syndrome control. However, this treatment considerably ameliorates proteinuria, systolic and diastolic blood pressure, and to a lesser extent creatinine clearance, during the time course (not shown) represented by the basal and final data in table 1. Also, as expected, serum levels of sodium and potassium were not affected either by diabetes or by treatment with pioglitazone (not shown).

The reduction in renal tubulointerstitial fibrosis by this regimen that we previously reported [22] was now confirmed, since the percentage of tubulointestitial fibrosis (mean $\pm \mathrm{SD}$ ) was $16.0 \pm 3.1$ for ZDF, $6.1 \pm 1.7^{*}$ for ZDF + pioglitazone $\left({ }^{*} \mathrm{p}<0.01 \mathrm{vs}\right.$. ZDF) and $2.5 \pm 1.3^{+} \mathrm{LZR}$ ${ }^{+} \mathrm{p}<0.01$ vs. all groups). Similarly, the percentage of glomerular sclerosis per glomerulus (mean $\pm \mathrm{SD}$ ) was now $26.9 \pm 5.2$ for $\mathrm{ZDF}, 7.7 \pm 2.3^{*}$ for $\mathrm{ZDF}+$ pioglitazone $\left({ }^{*} \mathrm{p}<0.01\right.$ vs. ZDF) and $1.1 \pm 0.4^{+}$for LZR $\left({ }^{+} \mathrm{p}<0.01\right.$ vs. all groups). In this setting, we now found that two additional markers, connective tissue growth factor (CTGF) (fig. 1a-d) and fibronectin (fig. 2a), were considerably overexpressed in the ZDF as compared to the LZR. This is seen in the representative micrographs for CTGF (the ones for fibronectin are not shown because of space limitations) and the quantitative estimations by image analysis for both proteins. CTGF showed granular cytoplasm distribu- 


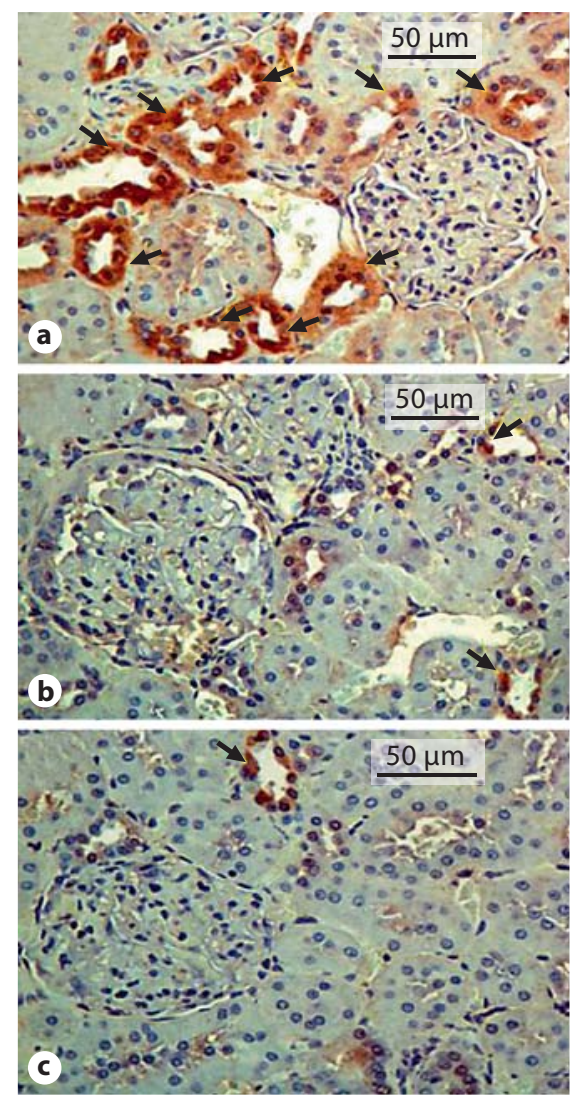

Fig. 1. A low dose of pioglitazone (PGT) normalized the expression of the fibrosis marker, connective tissue growth factor (CTGF), in renal tissue in type 2 diabetic rats. a-c Representative micrographs of renal tissue subjected to immunostaining. $\times 400$.

tion in distal tubular epithelial cells and cortical collecting tubules. Treatment with pioglitazone normalized the expression of CTGF, as confirmed by quantitative Western blot for the $38-\mathrm{kDa}$ band (fig. 1e), and also considerably diminished fibronectin levels (fig. 2a).

In turn, the anti-inflammatory effect of the drug that may mediate the antifibrotic response, also shown previously [22], was confirmed by the considerable decrease in interleukin- 6 not only in the glomerular area but also in epithelial tubular cells in the treated ZDF (IL-6) (fig. 2b) and the normalization of two other indicators, tumor necrosis factor- $\alpha$ (TNF- $\alpha$ ) and monocyte chemotactic protein (MCP-1) (fig. 2c, d, respectively). For the sake of space the representative micrographs are omitted, and only the bar graphs are shown. The positive immunostaining was detected for fibronectin in the cortex in the interstitium and in distal tubular epithelial cells, for IL-6 in mesangial cells as well as in distal tubular epithelial
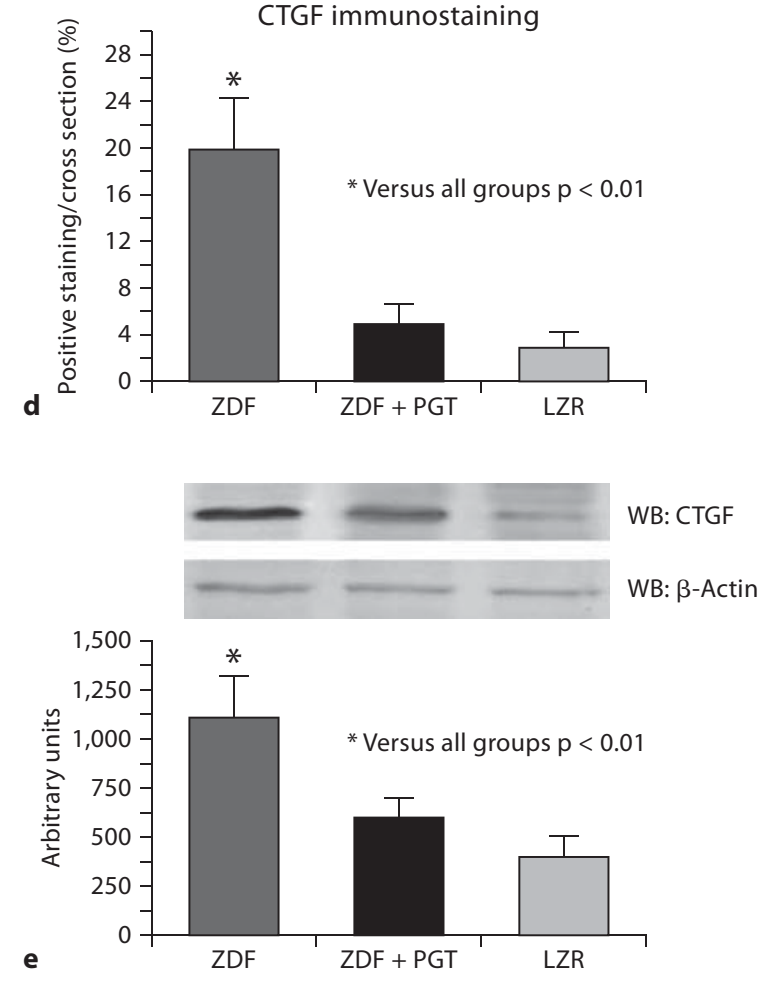

Arrows indicate overexpression of CTGF. a ZDF (Zucker diabetic fatty); b ZDF treated with PGT; c LZR (lean Zucker rats). d Bar graph representing the percentage of positive staining in all groups. e Western blot bands and densitometry.

cells, and for MCP1 in proximal and distal tubular epithelial cells and in mesangial cells. The ED1 determination previously reported for the corresponding rat groups was repeated in this new series and gave essentially similar results, where the number of positive cells per area (mean $\pm \mathrm{SD}$ ) was $17.4 \pm 4.1$ for ZDF, $3.4 \pm 1.0^{*}$ for ZDF + pioglitazone $\left({ }^{*} \mathrm{p}<0.01 \mathrm{vs}\right.$. ZDF) and $1.3 \pm 0.8^{+}$for LZR ${ }^{+} \mathrm{p}<0.01$ vs. all groups). Positive ED1 cell peritubular infiltration was detected mainly in the cortex.

Having confirmed in these groups of rats the improvement of kidney function and expanded the characterization of the anti-inflammatory and antifibrotic effects of pioglitazone at a dose that exerts a very poor glycemic control, we then examined the impact of diabetes and the drug on processes affecting the cellular content mainly in the glomeruli but also in the extraglomerular area. Megalin expression detected by immunofluorescence showed a linear/pseudolinear positive fluorescence pattern in 


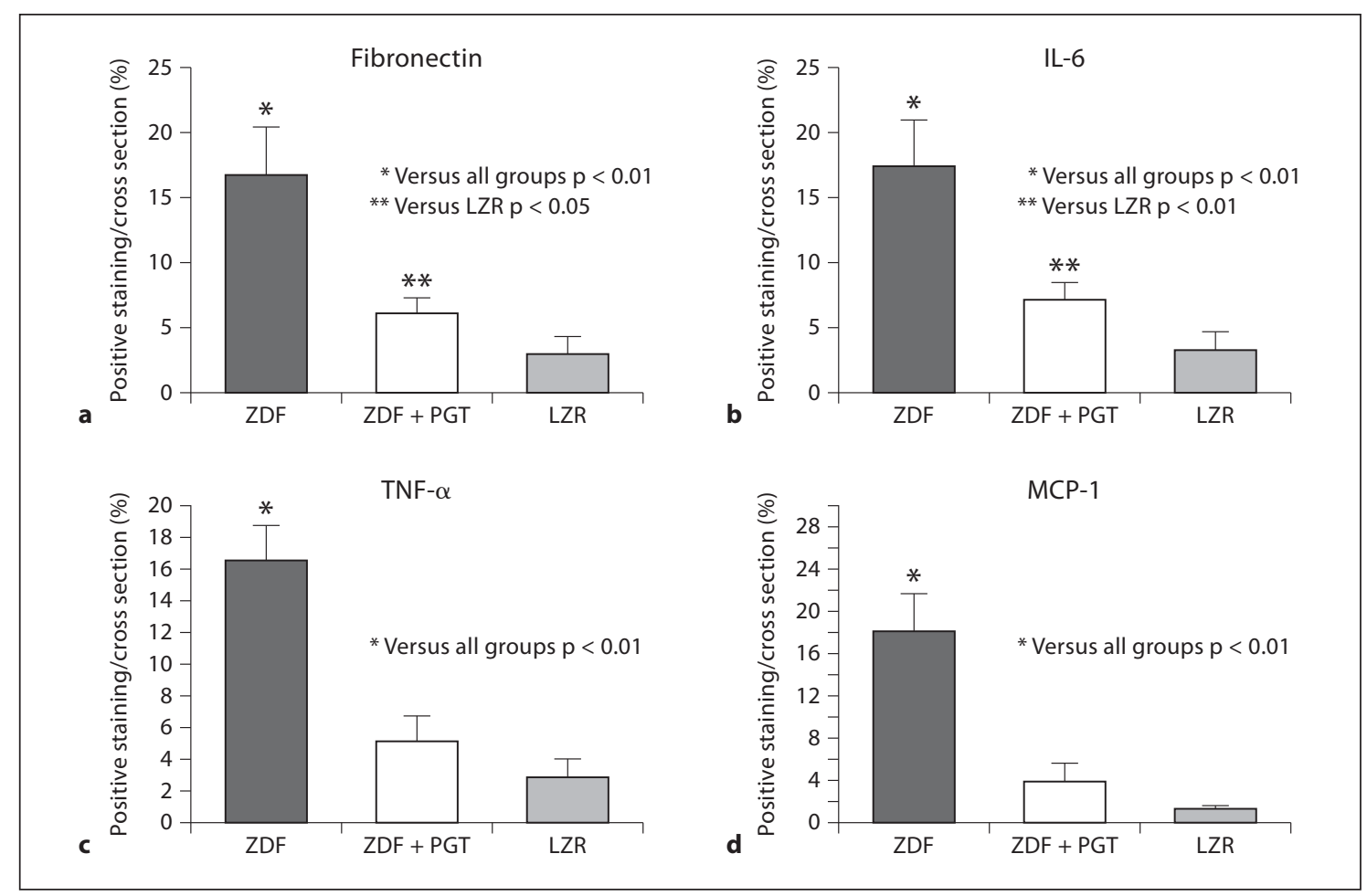

Fig. 2. A low dose of pioglitazone (PGT) normalized the expression of another fibrosis marker, fibronectin, and key inflammation markers in renal tissue in type 2 diabetic rats. Tissue sections were subjected to immunostaining for each of the markers and then subjected to quantitative image analysis. $\times 400$. The repre- sentative micrographs for the immunostained tissue sections are not included for the sake of space. Bar graphs represent the percentage of positive staining for a fibronectin, $\mathbf{b}$ IL-6, $\mathbf{c}$ TNF- $\alpha$, and d MCP-1. ZDF = Zucker diabetic fatty; ZDF + PGT = ZDF treated with PGT; LZR = lean Zucker rats. apical position of proximal tubular epithelial cells (fig. 3). This has revealed now that a tubular marker (not previously investigated) was restored by this treatment to the levels seen in the LZR, despite the still considerable hyperglycemia.

The cellular protective impact of this treatment was confirmed by the determination of the proliferation and apoptotic indexes, evaluated separately by the number cells positive for proliferating cell nuclear antigen (PCNA) (fig. 4a, b) and for caspase-3 (fig. 4c, d), respectively. The positive staining for both markers was evident in proximal tubular epithelial cells as well as in podocytes (fig. 4a, c). Type 2 diabetes in the ZDF induced a considerable and unexpected increase of the proliferation index that was normalized by pioglitazone to the values found in the LZR. Remarkably similar changes were found for the apoptotic index. This was confirmed by quantitative Western blot for the 34- and 17-kDa bands for PCNA and caspase-3, respectively (fig. $4 \mathrm{~b}, \mathrm{~d}$ ). When the ratio between both indexes was established, then the cellular turnover did not show significant differences between the ZDF (1.01 \pm 0.09$)$ and the LZR $(0.81 \pm 0.29)$, but pioglitazone increased this ratio $(1.35 \pm 0.30)$ moderately but significantly $(\mathrm{p}<0.01)$, suggesting that the drug enhanced cell replication over cell death.

The beneficial effects of pioglitazone were reaffirmed by the fact that a proapoptotic agent, iNOS, that in addition has pleiotropic effects on cell turnover, angiogenesis and fibrosis, was considerably upregulated in the ZDF kidney, but pioglitazone abrogated this expression to the negligible levels seen in the LZR (fig. 5a-d). The immunostaining was seen in the brush border of proximal tubular epithelial cells. Furthermore, cortical collecting tubules and podocytes showed granular cytoplasm distribution. The Western blot quantitative assay (fig. 5e) was in good agreement for the $130-\mathrm{kDa}$ band.

Since increased VEGF expression is known to be a main factor in the abnormal angiogenesis occurring in $\mathrm{DN}$, we estimated the effects of pioglitazone and found that the low-dose treatment normalized it to the values 


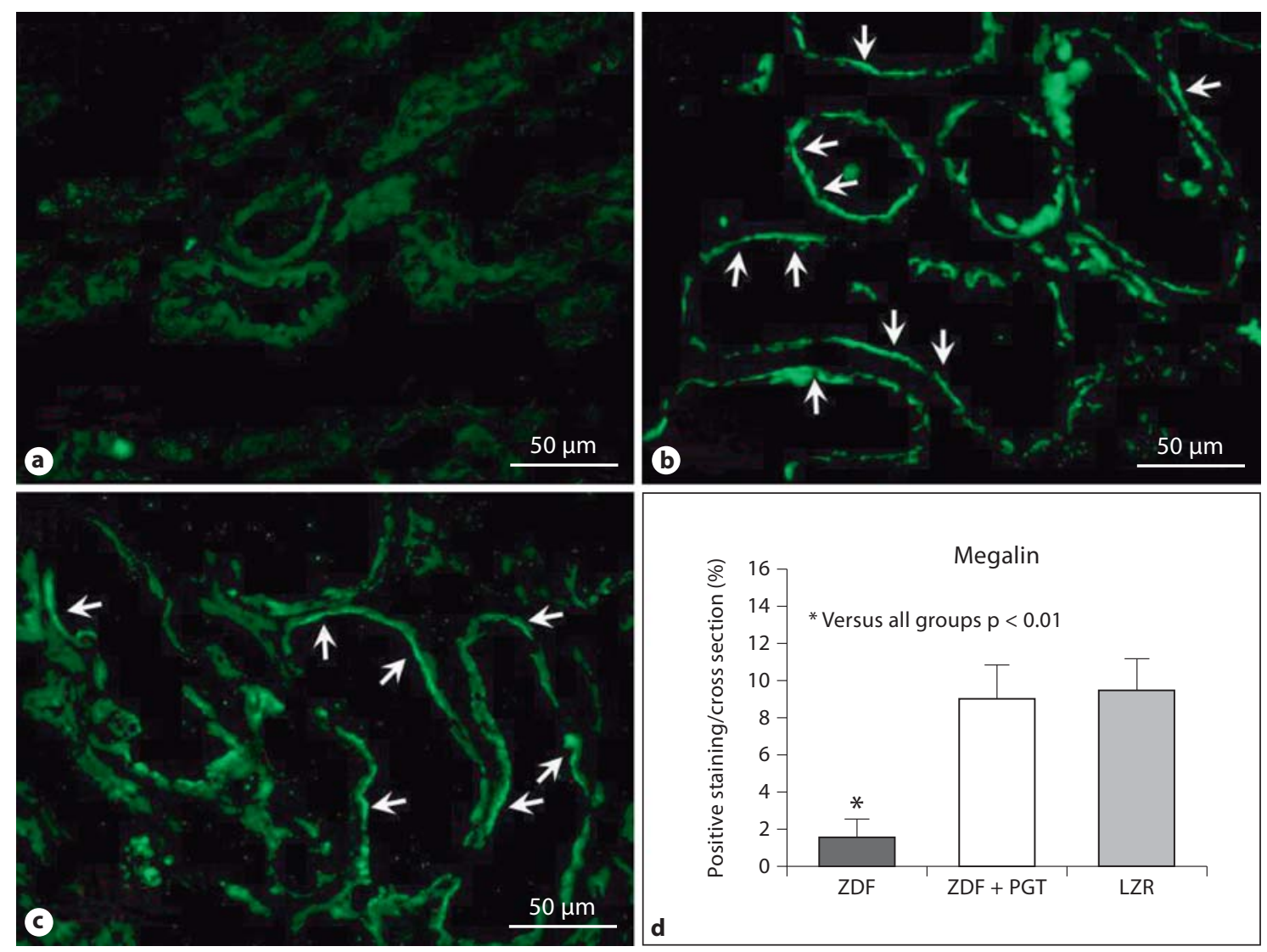

Fig. 3. A low dose of pioglitazone (PGT) normalized the expression of a key marker of tubular cells, megalin, in renal tissue in type 2 diabetic rats. a-c Representative micrographs of renal tissue subjected to immunofluorescent detection with IFTC. $\times 400$.
Arrows indicate expression of megalin in the epithelial tubular cells. a ZDF (Zucker diabetic fatty); b ZDF treated with PGT; c LZR (lean Zucker rats). d Bar graph representing the percentage of positive immunofluorescence in all groups. found in the LZR (fig. 6a-d), and this was accompanied as expected by the restoration of the levels of eNOS, a marker of endothelial function, that had been considerably downregulated by diabetes (fig. $7 \mathrm{a}-\mathrm{d}$ ). The positive immunostaining for VEGF was seen with granular cytoplasm distribution in distal tubular epithelial cells, cortical collecting tubules and podocytes, and for eNOS in the proximal tubular epithelial cells, cortical collecting tubules and podocytes with diffuse cytoplasm distribution. The immunohistochemical data was confirmed in both cases by quantitative Western blot (fig. 6e, 7e) for the 15and $140-\mathrm{kDa}$ bands for VEGF and eNOS, respectively. Interestingly, the ratio between eNOS and iNOS was increased by the drug from $0.21 \pm 0.08$ in the untreated $\mathrm{ZDF}$ to $6.43 \pm 3.76$ in the treated ZDF (p $<0.001$ ), as compared to $7.86 \pm 3.43$ in the LZR, as an indicator of a positive nitrergic (nitric oxide generator) balance that would favor vasodilatory over proapoptotic effects.

\section{Discussion}

Our previous work [22] had demonstrated that pioglitazone given at a low dose that did not exert any glycemic control in the OZR, and a very poor one in the ZDF, was still able to prevent $\mathrm{DN}$ in both strains, by reducing blood pressure and combating renal fibrosis, chronic inflammation and oxidative stress, as evidenced by the normalization of collagen, $\alpha$-smooth muscle actin, PAI-1, hemoxygenase, nephrin, ED1, and other markers. It is important to stress that in the OZR this dose of pioglitazone had virtually prevented the development of DN despite that hyperglycemia remained unchanged in this strain, at a level similar to the one observed then and now in the ZDF (around $250 \mathrm{mg} / \mathrm{dl}$ ). Here we confirm in the ZDF some of these findings with additional markers and expand the characterization of the drug effects by showing that it induces a positive balance of cell turnover and 
Fig. 4. a-d A low dose of pioglitazone (PGT) reduced the compensatory overexpression of a proliferation marker, proliferating cell nuclear antigen (PCNA), and normalized the expression of an apoptosis marker, caspase-3, in renal tissue in type 2 diabetic rats. Right panels: Representative micrographs of renal tissue subjected to immunostaining. $\times 400$. Arrows indicate expression in both the glomerular and epithelial cells, with positive nuclear staining. Left panels: a, c Bar graphs representing the number of cells with positive immunostaining for PCNA and caspase-3 respectively in all groups. b, d Western blots and densitometric estimations. $\mathrm{ZDF}=$ Zucker diabetic fatty rats; ZDF + PGT = ZDF treated with PGT; LZR = lean Zucker rats.

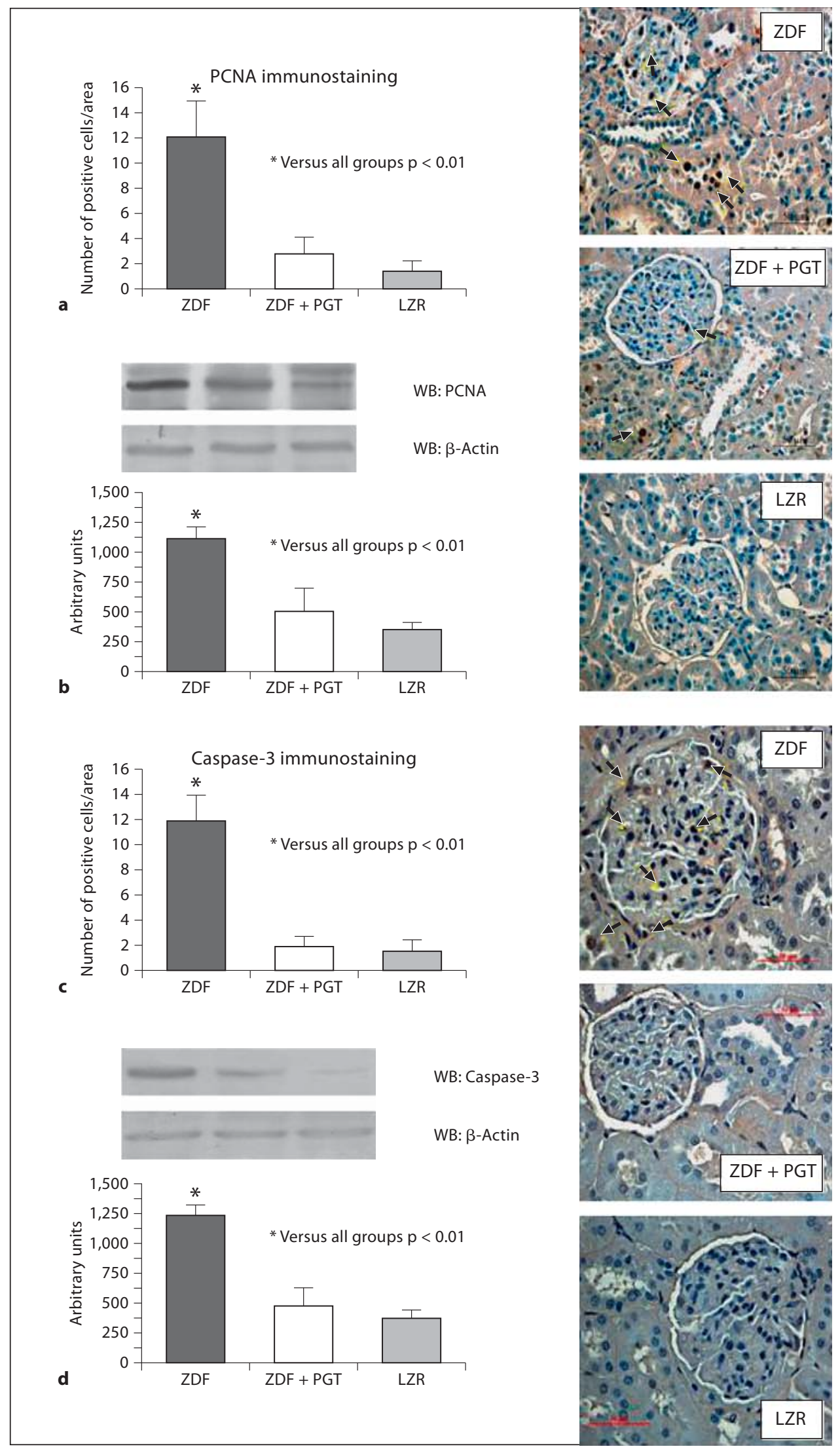




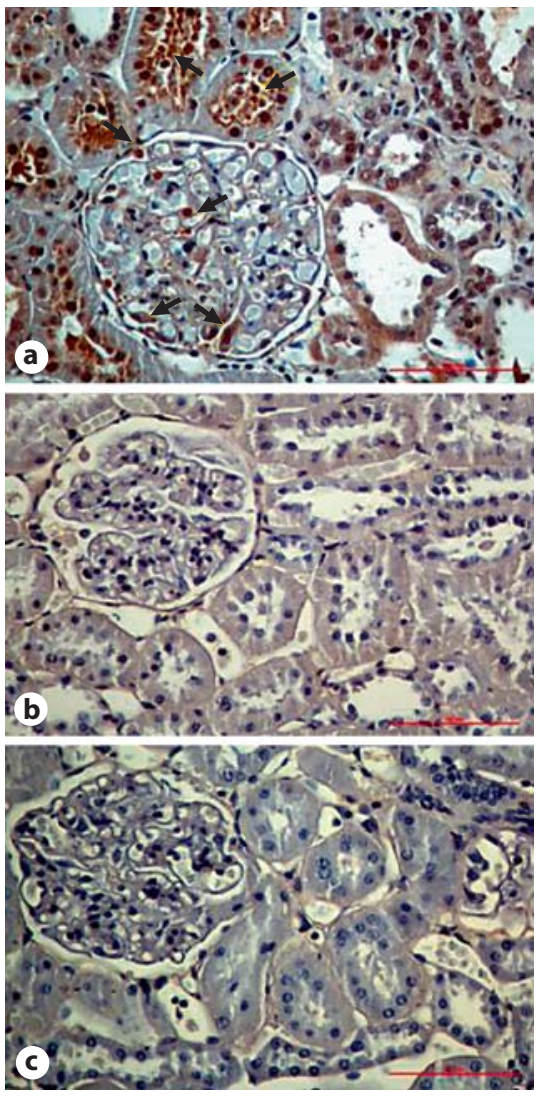

Fig. 5. A low dose of pioglitazone (PGT) normalized the expression of a potentially proapoptotic factor, inducible nitric oxide synthase (iNOS), in renal tissue in type 2 diabetic rats. a-c Representative micrographs of renal tissue subjected to immuno-
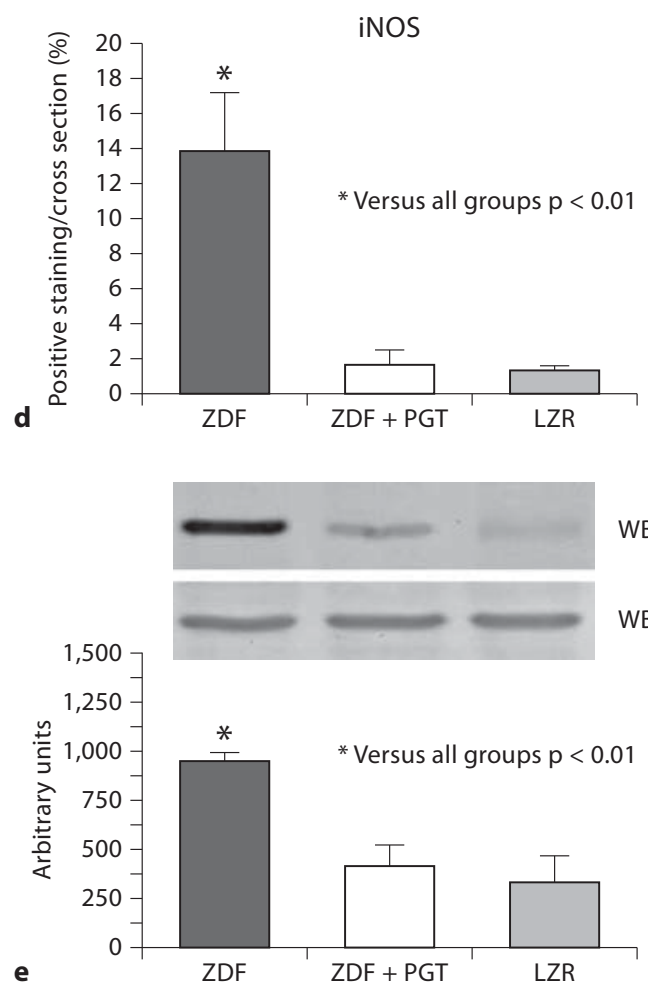

staining. $\times 400$. a ZDF (Zucker diabetic fatty); b ZDF treated with PGT; c LZR (lean Zucker rats). d Bar graph representing the percentage of positive immunostaining in all groups. e Western blot and densitometric estimations. counteracts indicators of tubular pathology, abnormal angiogenesis, endothelial damage, and inflammatory nitrergic imbalance. The near normalization by low-dose pioglitazone of both proteinuria and blood pressure is in excellent agreement with the effects observed on all these histopathological markers of renal tissue damage. This proteinuria control may also contribute to reduce tubulointerstitial inflammation.

One of the key findings of the current work is the normalization of CTGF and fibronectin levels by this treatment. CTGF is a downstream mediator of TGF- $\beta_{1}$, the key profibrotic factor in the diabetic kidney that we had shown to be downregulated by low-dose pioglitazone [22], and that leads to the also previously described excessive collagen I and III production, corrected by pioglitazone. CTGF is mainly produced in the podocytes [26] and its $\alpha$-smooth muscle actin levels are increased in diabetic patients and mice, as well as in urine in the mice
$[27,28]$. Moreover, $\alpha$-smooth muscle actin CTGF is an independent predictor of end-stage renal disease and mortality in patients with type 1 diabetes [29]. Fibronectin is also a well-recognized marker of fibrosis in DN [30]. The fibronectin normalization with our treatment in the ZDF is in perfect agreement with CTGF normalization, since CTGF induced fibronectin expression in mesangial cells concurrent with collagen deposition [31]. No studies are available in vivo on the effects of pioglitazone on both markers in $\mathrm{DN}$, although another thiazolidinedione, rosiglitazone, did reduce fibronectin expression in a lowdose streptozotocin-induced diabetes in the mouse, in the absence of glycemic control since this is a model of mild type 1 diabetes [32].

The prevention of the increase of proinflammatory markers by pioglitazone at low doses, previously shown just with ED1 [22] and confirmed in the current work, has now been more conclusively proven by finding similar ef- 


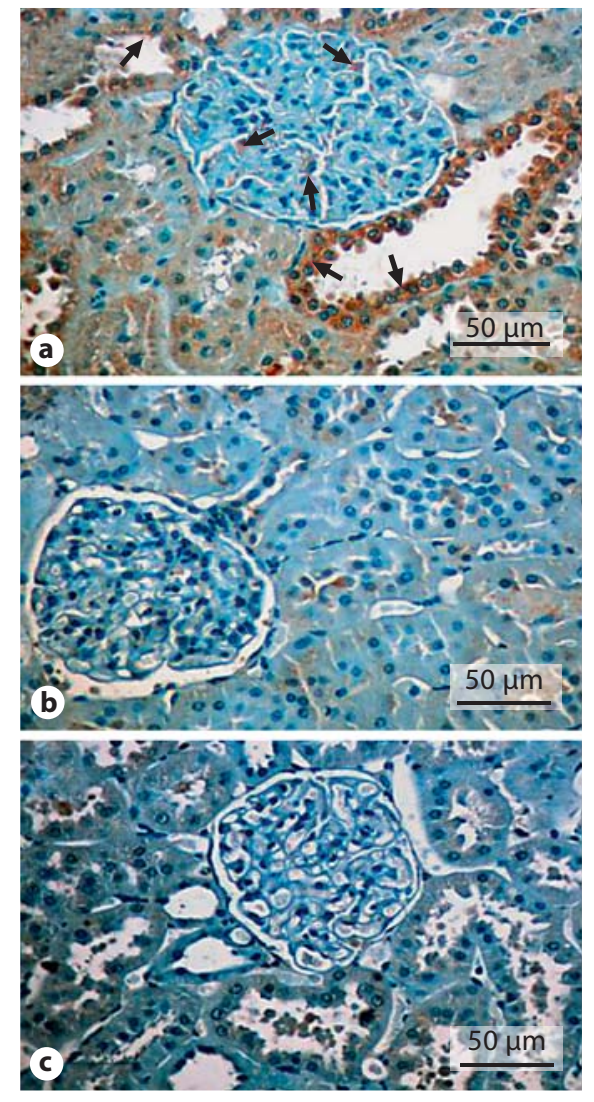

Fig. 6. A low dose of pioglitazone (PGT) normalized the expression of an angiogenesis marker, vascular endothelial growth factor (VEGF), in this case denoting abnormal angiogenesis, in renal tissue in type 2 diabetic rats. a-c Representative micrographs of renal tissue subjected to immunostaining. $\times 400$. Arrows indicate
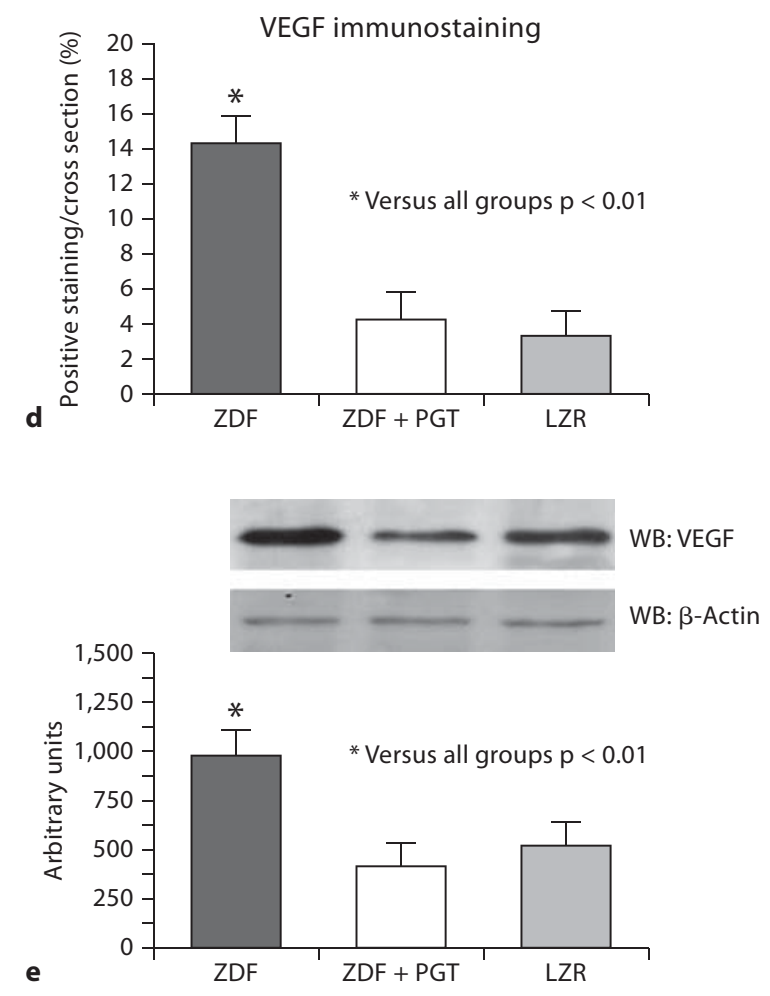

expression mainly in epithelial tubular cells. a ZDF (Zucker diabetic fatty); b ZDF treated with PGT; c LZR (lean Zucker rats). d Bar graph representing the percentage of positive immunostaining in all groups. e Western blot and densitometric estimations. fects on other key markers of inflammation. They include either cytokines, such as TNF- $\alpha$ and IL-6, or a chemotaxic factor, MCP-1, which are well known to be associated with DN $[12,33]$. Pioglitazone at doses exerting glycemic control, and to a lower extent rosiglitazone, lowered serum TNF- $\alpha$ in diabetic patients in association with reduced albuminuria [34], but no changes were observed in another study, even if IL- 6 was reduced [35]. In contrast with these conflicting results for TNF- $\alpha$, rosiglitazone does reduce urinary MCP-1 in streptozotocininduced diabetic rats [36]. However, no in vivo studies are available for pioglitazone at any dose on IL-6 or MCP-1, and in general for any other thiazolidinedione at suboptimal doses, or again at any dose on the diabetic kidney, as opposed to circulating cytokines.

Along with our innovative results is the normalization of the tubular marker megalin by low doses of pio- glitazone in the kidney of the ZDF, that shows an improvement of tubular cell homeostasis in concurrence with the previously reported prevention of glomerular damage detected by nephrin immunostaining [22]. Megalin is an endocytic receptor on the apical membranes of proximal tubule cells which is involved in the reabsorption of proteins filtered by the glomeruli [37]. Very few studies have been conducted so far with this marker despite its functional importance, and only one report in vivo in the type 1 diabetic kidney showing its increase with an anti-TGF- $\beta_{1}$ strategy, in association with reduced urinary albumin excretion and reduction of collagen IV expression, independently from glycemic control [38]. Aberrant shedding of megalin was also shown type 1 diabetic patients with microalbuminuria [39]. However, no reports are available on the effect of thiazolidinediones on this marker in DN. 


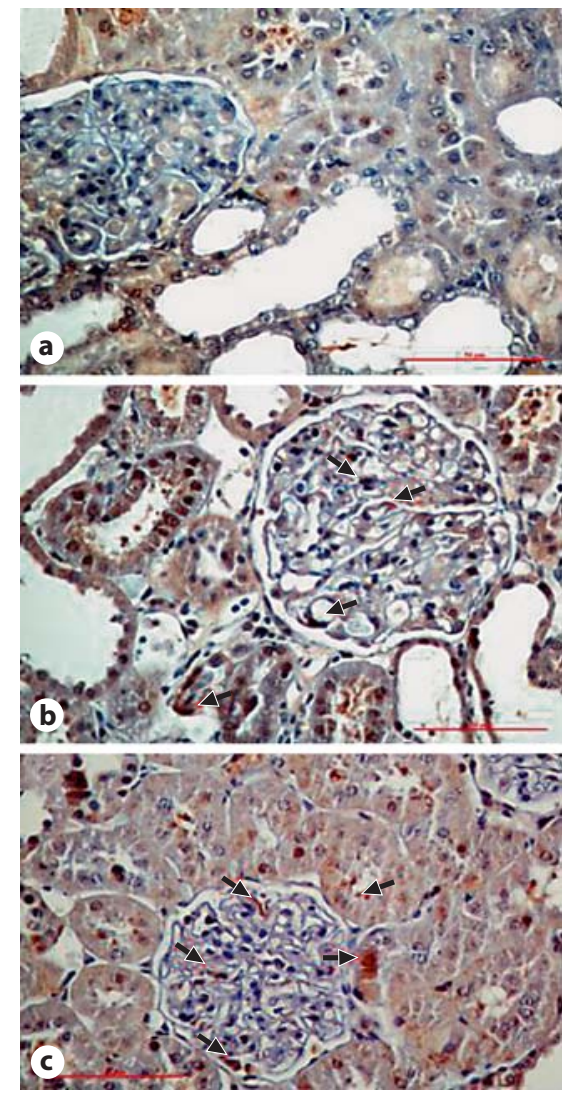

Fig. 7. A low dose of pioglitazone (PGT) normalized the expression of a marker of endothelial integrity and function, endothelial nitric oxide synthase (eNOS), in renal tissue in type 2 diabetic rats. a-c Representative micrographs of renal tissue subjected to immunostaining. $\times 400$. Arrows indicate expression not only
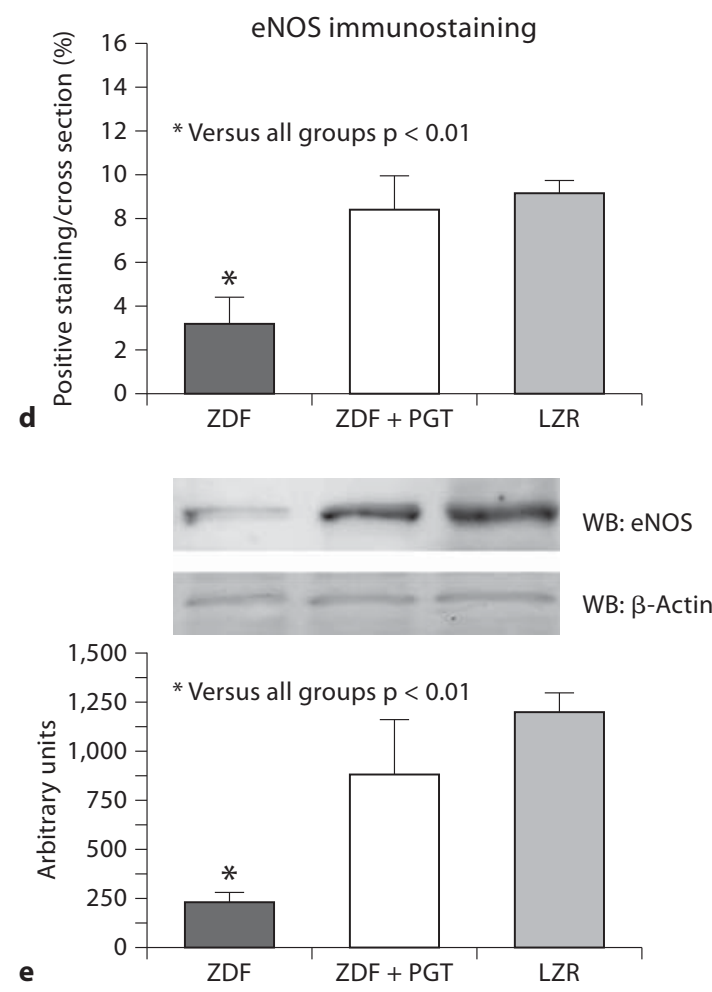

in the glomerular area but also in epithelial tubular cells. a ZDF (Zucker diabetic fatty); b ZDF treated with PGT; c LZR (lean Zucker rats). $\mathbf{d}$ Bar graph representing the percentage of positive immunostaining in all groups. e Western blot and densitometric estimations.
One of the main features of DN is the loss of both tubular and glomerular cells discussed above, that appears to be the target of the recently demonstrated amelioration of type $2 \mathrm{DN}$ in OLEFT rats by low-dose pioglitazone, via local cell cycle-dependent mechanisms and apoptosis (G1-phase cell cycle arrest, and Bcl-2 levels), mainly in podocytes, and very importantly without affecting $\mathrm{HbA}_{1 \mathrm{c}}$ levels [23]. Our results on the increase of the cell replication/apoptosis balance in glomerular regions, within an overall reduced cell turnover, support this concept. We are not aware of any other study of thiazolidinediones on cell turnover in $\mathrm{DN}$, although the paradoxical reduction of PCNA in this work agrees also with prior observations on troglitazone in 5/6 nephrectomy [40], or on thiazolidinediones effects on apoptosis.

Our demonstration of renal VEGF reduction has important implications, since this growth factor overpro- duction involved in abnormal angiogenesis leads to vasculopathy associated with aberrant growth of new blood vessels that plays a crucial role in nephropathy [41]. This agrees with the single study we could identify for any thiazolidinedione (pioglitazone too in this case), that was performed in OLEFT rats but with doses improving insulin sensitivity [21]. The increase in eNOS observed in the current work, somehow paradoxical in terms of the VEGF reduction, is however logical by suggesting that this treatment increases nitric oxide bioavailability and corrects endothelial dysfunction in existing vessels [12] without inducing neoangiogenesis, and possibly being responsible for the early phase glomerular hyperfiltration in DN [41]. The latter study showed an increase of eNOS in the early phase of diabetes in a mouse model, and pioglitazone reduced eNOS and corrected glomerular hyperfiltration, but the effects on the more advanced stage 
were not investigated. We are not aware of any other study on renal eNOS levels being affected by thiazolidinediones in DN.

Finally, our results on renal iNOS reduction in DN are also novel in terms of thiazolidinedione effects. They would suggest that the antiapoptotic effects of PPAR- $\gamma$ agonists in the kidney would be in part due to the abrogation of iNOS expression, that by producing sustained excessive levels of nitric oxide and peroxynitrite would act as proapoptotic and stimulator of lipid peroxidation in this setting [42]. However, this needs further investigation, since iNOS has been claimed to act as antifibrotic agent in the vascular system [43] and even in the kidney in the streptozotocin-induced diabetic iNOS knockout mouse where renal fibrosis is exacerbated in comparison to the wild-type mouse [44]. Moreover, depletion of tetrahydrobiopterin, a key co-factor of iNOS activity, appears to be involved in the development of type $2 \mathrm{DN}$ in OLEFT rats [45], so the benefit/damage balance of the observed abrogation by pioglitazone of iNOS expression remains to be determined.

The studies showing beneficial effects of thiazolidinediones on DN in type 1 animal models [16, 17], where these drugs do not lower glycemia, prove their direct action on the kidney unrelated to glycemic control. Higher doses of thiazolidinediones that did exert glycemic control in patients and rat models but were more effective than insulin or metformin in renoprotection also supported this assumption [12]. Moreover, pioglitazone has been recently shown to protect against non-diabetic chronic kidney disease in experimental models where glycemic control does not play any role, and specifically in renal injury in aging, by reducing proteinuria, improving GFR, decreasing sclerosis and systemic and renal oxidative stress, and improving mitochondrial function, through local effects on the kidney [46]. Antifibrotic and protective effects of pioglitazone independent of glycemic control were also shown locally in other tissues, such as in the aging penile corpora cavernosa [47].

In the present work, in contrast to the clear-cut lack of glycemic control by low-dose pioglitazone in the OZR that per se supported our claim of independent local effects of pioglitazone on the kidney [22], there was in the ZDFR a significant reduction of glycemia. Even if these values did not go below the previously observed threshold of $243 \mathrm{mg} / \mathrm{dl}$, we cannot exclude in the ZDFR that part of the beneficial effects we have observed in $\mathrm{DN}$ are due to reducing the severity of the diabetes. However, in the context of the collective evidence on the protective effects of pioglitazone and other thiazolidinediones on the kidney from models of type 1 diabetes and non-diabetic conditions, and even on other types of fibrosis, and our own previous results in the OZR and ZDFR, one may speculate that our findings on type $2 \mathrm{DN}$ animal models result, at least in part, from a mechanism additional to the widely accepted systemic glycemic control [12]. Similarly, although a systemic effect on the lowering of blood pressure observed here cannot be denied, the improvement of the nephropathy by alternative local mechanisms would contribute to it and reinforce the process.

Our assumption that still requires direct proof is that the binding of ligands such as thiazolidinediones to PPARs in the kidney glomerular, tubular, mesangial, and endothelial cells [48-50] would contribute in DN to triggering not just the previously demonstrated anti-inflammatory, antioxidative stress, and antifibrotic effects, but even more pleiotropically, by affecting cell cycle homeostasis, specific growth factor modulation (VEGF), and nitrergic balance (eNOS/iNOS), thus confirming many predictions from vascular studies.

\section{Acknowledgements}

This work was supported by an investigator-initiated grant from Takeda Pharmaceuticals North America, Inc., and grants from the American Diabetes Association (\#7-05-RA-44 ADA), and NIH (NIHR01 DK53069), to N.G.C.

J.E.T. and F.P.D. are career investigators from the Consejo Nacional de Investigaciones Científicas y Tecnologicas of Argentina (CONICET) and received grant support from the University of Buenos Aires (UBA), CONICET and Agencia Nacional de Promocion Científica y Tecnologica of Argentina. J.F.G. is a research fellow from CONICET.

References

$\checkmark 1$ Abe M, Okada K, Kikuchi F, Matsumoto $\mathrm{K}$ : Clinical investigation of the effects of pioglitazone on the improvement of insulin resistance and blood pressure in type 2 diabetic patients undergoing hemodialysis. Clin Nephrol 2008;70:220-228.

12 Schernthaner G: Kidney disease in diabetology: lessons from 2007. Nephrol Dial Transplant 2008;23:1112-1115.

-3 Sarafidis PA: Obesity, insulin resistance and kidney disease risk: insights into the relationship. Curr Opin Nephrol Hypertens 2008; 17:450-456.

4 Rodriguez WE, Tyagi N, Joshua IG, Passmore JC, Fleming JT, Falcone JC, Tyagi SC: Pioglitazone mitigates renal glomerular vascular changes in high-fat, high-calorie-induced type 2 diabetes mellitus. Am J Physiol Renal Physiol 2006;291:F694-F701. 
-5 McCarthy KJ, Routh RE, Shaw W, Walsh K, Welbourne TC, Johnson JH: Troglitazone halts diabetic glomerulosclerosis by blockade of mesangial expansion. Kidney Int 2000;58:2341-2350.

-6 Buckingham RE, Al-Barazanji KA, Toseland $\mathrm{CD}$, Slaughter M, Connor SC, West A, Bond B, Turner NC, Clapham JC: Peroxisome proliferator-activated receptor- $\gamma$ agonist, rosiglitazone, protects against nephropathy and pancreatic islet abnormalities in Zucker fatty rats. Diabetes 1998;47:1326-1334.

7 Buckingham RE: Thiazolidinediones: pleiotropic drugs with potent anti-inflammatory properties for tissue protection. Hepatol Res 2005;33:167-170

-8 Panchapakesan U, Chen XM, Pollock CA: Drug insight: thiazolidinediones and diabetic nephropathy - relevance to renoprotection. Nat Clin Pract Nephrol 2005;1:33-43.

-9 Qian Y, Feldman E, Pennathur S, Kretzler M, Brosius FC 3rd: From fibrosis to sclerosis: mechanisms of glomerulosclerosis in diabetic nephropathy. Diabetes 2008;57:14391445.

10 Swaminathan S, Shah SV: Novel approaches targeted toward oxidative stress for the treatment of chronic kidney disease. Curr Opin Nephrol Hypertens 2008; 17:143-148.

11 Simonson MS: Phenotypic transitions and fibrosis in diabetic nephropathy. Kidney Int 2007;71:846-854.

12 Sarafidis PA, Bakris GL: Protection of the kidney by thiazolidinediones: an assessment from bench to bedside. Kidney Int 2006; 70 : 1223-1233.

13 Agarwal R, Saha C, Battiwala M, Vasavada N, Curley T, Chase SD, Sachs N, Semret MH: A pilot randomized controlled trial of renal protection with pioglitazone in diabetic nephropathy. Kidney Int 2005;68:285-292.

14 Katavetin P, Eiam-Ong S, Suwanwalaikorn $S$ : Pioglitazone reduces urinary protein and urinary transforming growth factor- $\beta$ excretion in patients with type 2 diabetes and overt nephropathy. J Med Assoc Thai 2006; 89:170-177.

15 Nakamura T, Sugaya T, Kawagoe Y, Ueda Y, Koide H: Effect of pioglitazone on urinary liver-type fatty acid-binding protein concentrations in diabetes patients with microalbuminuria. Diabetes Metab Res Rev 2006;22: 385-389.

16 Ohga S, Shikata K, Yozai K, Okada S, Ogawa D, Usui H, Wada J, Shikata Y, Makino H: Thiazolidinedione ameliorates renal injury in experimental diabetic rats through antiinflammatory effects mediated by inhibition of NF- $\mathrm{KB}$ activation. Am J Physiol Renal Physiol 2007;292:F1141-F1150.

- 17 Yamashita H, Nagai Y, Takamura T, Nohara E, Kobayashi K: Thiazolidinedione derivatives ameliorate albuminuria in streptozotocin-induced diabetic spontaneous hypertensive rat. Metabolism 2002;51:403-408.
18 Peterson RG, Shaw WN, Neel MA: Zucker diabetic fatty as a model for non-insulin-dependent diabetes mellitus. ILAR News 1990; 32:16-19.

>19 Li Y, Qi Y, Kim MS, Xu KZ, Huang TH, Rong $\mathrm{X}$, Murray M, Yamahara J: Increased renal collagen cross-linking and lipid accumulation in nephropathy of Zucker diabetic fatty rats. Diabetes Metab Res Rev 2008;24:498506.

20 Dominguez J, Wu P, Packer CS, Temm C, Kelly KJ: Lipotoxic and inflammatory phenotypes in rats with uncontrolled metabolic syndrome and nephropathy. Am J Physiol Renal Physiol 2007;293:F670-F679.

21 Ko GJ, Kang YS, Han SY, Lee MH, Song HK, Han KH, Kim HK, Han JY, Cha DR: Pioglitazone attenuates diabetic nephropathy through an anti-inflammatory mechanism in type 2 diabetic rats. Nephrol Dial Transplant 2008;23:2750-2760.

22 Toblli JE, Ferrini MG, Cao G, Vernet D, Angerosa M, Gonzalez-Cadavid NF: Antifibrotic effects of pioglitazone on the kidney in a rat model of type 2 diabetes mellitus. Nephrol Dial Transplant 2009;24:23842391

23 Okada T, Wada J, Hida K, Eguchi J, Hashimoto I, Baba M, Yasuhara A, Shikata K, Makino H: Thiazolidinediones ameliorate diabetic nephropathy via cell cycle-dependent mechanisms. Diabetes 2006;55:16661677.

24 Kovanecz I, Nolazco G, Ferrini MG, Toblli JE, Heydarkhan S, Vernet D, Rajfer J, Gonzalez-Cadavid NF: Pioglitazone prevents corporal veno-occlusive dysfunction in a rat model of type 2 diabetes mellitus. BJU Int 2006;98:116-124.

25 Patrakka J, Tryggvason K: New insights into the role of podocytes in proteinuria. Nat Rev Nephrol 2009;5:463-468.

26 Chiarelli F, Gaspari S, Marcovecchio ML: Role of growth factors in diabetic kidney disease. Horm Metab Res 2009;41:585-593.

27 Gilbert RE, Akdeniz A, Weitz S, Usinger WR, Molineaux C, Jones SE, Langham RG Jerums G: Urinary connective tissue growth factor excretion in patients with type 1 diabetes and nephropathy. Diabetes Care 2003; 26:2632-2636.

-28 Riser BL, Cortes P, DeNichilo M, Deshmukh PV, Chahal PS, Mohammed AK, Yee J, Kahkonem D: Urinary CCN2 as a possible predictor of diabetic nephropathy: preliminary report. Kidney Int 2003;64:451-458.

29 Nguyen TQ, Tarnow L, Jorsal A, Oliver N, Roestenberg P, Ito Y, Parving HH, Rossing $\mathrm{P}$, van Nieuwenhoven FA, Goldschmeding R: Alpha-smooth muscle actin connective tissue growth factor is an independent predictor of end-stage renal disease and mortality in type 1 diabetic nephropathy. Diabetes Care 2008;31:1177-1182.
30 Nasrallah R, Robertson SJ, Hébert RL: Chronic COX inhibition reduces diabetesinduced hyperfiltration, proteinuria, and renal pathological markers in 36-week B6-Ins2 mice. Am J Nephrol 2009;30:346-353.

- 31 Riser BL, Denichilo M, Cortes P, Baker C, Grondin JM, Yee J, Narins RG: Regulation of connective tissue growth factor activity in cultured rat mesangial cells and its expression in experimental diabetic glomerulosclerosis. J Am Soc Nephrol 2000;11:25-38.

- 32 Zhang H, Saha J, Byun J, Schin M, Lorenz M, Kennedy RT, Kretzler M, Feldman EL, Pennathur S, Brosius FC 3rd: Rosiglitazone reduces renal and $\alpha$-smooth muscle actin markers of oxidative injury and reverses urinary metabolite abnormalities in the amelioration of diabetic nephropathy. Am J Physiol Renal Physiol 2008;295:F1071-F1081.

33 Niewczas MA, Ficociello LH, Johnson AC, Walker W, Rosolowsky ET, Roshan B, Warram JH, Krolewski AS: Serum concentrations of markers of TNF- $\alpha$ and Fas-mediated pathways and renal function in non-proteinuric patients with type 1 diabetes. Clin J Am Soc Nephrol 2009;4:62-70.

-34 Vijay SK, Mishra M, Kumar H, Tripathi K: Effect of pioglitazone and rosiglitazone on mediators of endothelial dysfunction, markers of angiogenesis and inflammatory cytokines in type-2 diabetes. Acta Diabetol 2009; 46:27-33.

35 Agarwal R: Anti-inflammatory effects of short-term pioglitazone therapy in men with advanced diabetic nephropathy. Am J Physiol Renal Physiol 2006;290:F600-F605.

36 Zheng M, Ye S, Zhai Z, Chen Y, Li X, Yang G, Fan A, Wang Y: Rosiglitazone protects diabetic rats against kidney disease through the suppression of renal moncyte chemoattractant protein-1 expression. J Diabetes Complications 2009;23:124-129.

37 Saito A, Takeda T, Hama H, Oyama Y, Hosaka K, Tanuma A, Kaseda R, Ueno M, Nishi S, Ogasawara S, Gondaira F, Suzuki Y, Gejyo F: Role of megalin, a proximal tubular endocytic receptor, in the pathogenesis of diabetic and metabolic syndrome-related nephropathies: protein metabolic overload hypothesis. Nephrology (Carlton) 2005; 10(suppl):S26-S31.

38 Russo LM, del Re E, Brown D, Lin HY: Evidence for a role of transforming growth factor (TGF)- $\beta_{1}$ in the induction of postglomerular albuminuria in diabetic nephropathy: amelioration by soluble TGF- $\beta$ type II receptor. Diabetes 2007;56:380-388.

- 39 Thrailkill KM, Nimmo T, Bunn RC, Cockrell GE, Moreau CS, Mackintosh S, Edmondson RD, Fowlkes JL: Microalbuminuria in type 1 diabetes is associated with enhanced excretion of the endocytic multiligand receptors megalin and cubilin. Diabetes Care 2009;32:1266-1268. 
40 Ma LJ, Marcantoni C, Linton MF, Fazio S, Fogo AB: Peroxisome proliferator-activated receptor- $\gamma$ agonist troglitazone protects against nondiabetic glomerulosclerosis in rats. Kidney Int 2001;59:1899-1910.

-41 Biscetti F, Straface G, Pitocco D, Zaccardi F, Ghirlanda G, Flex A: Peroxisome proliferator-activated receptors and angiogenesis. Nutr Metab Cardiovasc Dis 2009;19:751759.

42 Stadler K, Bonini MG, Dallas S, Jiang J, Radi R, Mason RP, Kadiiska MB: Involvement of inducible nitric oxide synthase in hydroxyl radical-mediated lipid peroxidation in streptozotocin-induced diabetes. Free Radic Biol Med 2008; 15:866-874.

43 Ferrini MG, Davila HH, Valente EG, Gonzalez-Cadavid NF, Rajfer J: Aging-related induction of inducible nitric oxide synthase is vasculo-protective to the arterial media. Cardiovasc Res 2004;61:796-805.
44 Trachtman H, Futterweit S, Pine E, Mann J, Valderrama E: Chronic diabetic nephropathy: role of inducible nitric oxide synthase. Pediatr Nephrol 2002;17:20-29.

-45 Okumura M, Masada M, Yoshida Y, Shintaku H, Hosoi M, Okada N, Konishi Y, Morikawa T, Miura K, Imanishi M: Decrease in tetrahydrobiopterin as a possible cause of nephropathy in type 2 diabetic rats. Kidney Int 2006;70:471-476.

46 Yang HC, Deleuze S, Zuo Y, Potthoff SA, Ma LJ, Fogo AB: The PPAR- $\gamma$ agonist pioglitazone ameliorates aging-related progressive renal injury. J Am Soc Nephrol 2009;20: 2380-2388.

47 Kovanecz I, Ferrini MG, Davila HH, Rajfer J, Gonzalez-Cadavid NF: Pioglitazone ameliorates penile corpora veno-occlusive dysfunction in the aged rat. BJU Int 2007;100:867874.
48 Sato K, Sugawara A, Kudo M, Uruno A, Ito S, Takeuchi K: Expression of peroxisome proliferators activated receptor isoform proteins in the rat kidney. Hypertens Res 2004;27: 417-425.

49 Yoshimura R, Matsuyama M, Segawa Y, Tsuchida K, Takemoto Y, Kuratsukuri K, Kawahito Y, Shinka T, Sano H, Nakatani T: Study of peroxisome proliferator-activated receptor- $\gamma$ in renal ischemia-reperfusion injury. Transplant Proc 2004;36:1946-1948.

$50 \mathrm{Li}$ X, Kimura H, Hirota K, Sugimoto H, Kimura N, Takahashi N, Fujii H, Yoshida H: Hypoxia reduces the expression and anti-inflammatory effects of peroxisome proliferator-activated receptor- $\gamma$ in human proximal renal tubular cells. Nephrol Dial Transplant 2007;22:1041-1051 